The AAPS Journal 2006; 8 (4) Article 86 (http://www.aapsj.org).

\title{
Corrigendum: Insights Into the Effects of Hyperlipoproteinemia on Cyclosporine A Biodistribution and Relationship to Renal Function
}

Submitted: November 17, 2006; Accepted: November 17, 2006; Published: December 28, 2006

Hamidreza Montazeri Aliabadi, ${ }^{1}$ Tara J. Spencer, ${ }^{1}$ Parvin Mahdipoor, ${ }^{1}$ Afsaneh Lavasanifar, ${ }^{1}$ and Dion R. Brocks ${ }^{1}$

AAPS Journal. 2006;8(4):E672-E681. DOI: 10.1208/aapsj080477

The mass units for the $y$-axis in Figure 1 should have read micrograms and not nanograms. 